\title{
Correlation between the surface chemistry and the atmospheric corrosion of AZ31, AZ80 and AZ91D magnesium alloys
}

\author{
S. Feliú Jr ${ }^{a}$, A. Pardo ${ }^{b,}$, M.C. Merino ${ }^{b}$, A.E. Coy $^{c}$, F. Viejo ${ }^{c}$ and R. Arrabal ${ }^{c}$ \\ ${ }^{a}$ Centro Nacional de Investigaciones Metalúrgicas CSIC, Avda. Gregorio del Amo 8, 28040 Madrid, \\ Spain \\ ${ }^{b}$ Departamento de Ciencia de Materiales, Facultad de Química, Universidad Complutense, 28040, \\ Madrid, Spain \\ ${ }^{c}$ Corrosion and protection Centre, School of Materials, The University of Manchester, P.O. Box 88, \\ Sackville Street, Manchester, M60 1QD, United Kingdom \\ "Corresponding author. Tel: 341 3944348; Fax: 3413944357 \\ E-mail: anpardo@quim.ucm.es
}

\begin{abstract}
X-ray photoelectron spectroscopy (XPS) was used in order to investigate the correlation between the surface chemistry and the atmospheric corrosion of AZ31, AZ80 and AZ91D magnesium alloys exposed to $98 \%$ relative humidity at $50^{\circ} \mathrm{C}$. Commercially pure magnesium, used as the reference material, revealed $\mathrm{MgO}, \mathrm{Mg}(\mathrm{OH})_{2}$ and tracers of magnesium carbonate in the air-formed film. For the AZ80 and AZ91D alloys, the amount of magnesium carbonate formed on the surface reached similar values to those of $\mathrm{MgO}$ and $\mathrm{Mg}(\mathrm{OH})_{2}$. A linear relation between the amount of magnesium carbonate formed on the surface and the subsequent corrosion behaviour in the humid environment was found. The AZ80 alloy revealed the highest amount of magnesium carbonate in the air-formed film and the highest atmospheric corrosion resistance, even higher than the AZ91D alloy, indicating that aluminium distribution in the alloy microstructure influenced the amount of magnesium carbonate formed.
\end{abstract}

KEYWORDS: Magnesium/aluminium alloys, XPS, corrosion, humidity 


\section{INTRODUCTION}

The alloy composition/microstructure and the nature of the passive film influence the corrosion mechanism of magnesium alloys exposed to aqueous solutions [1-7] and simulated saline atmospheres [8-12]. In general, corrosion attack is revealed between phases with different electrochemical behaviour, and degradation is favoured if there are chlorided ions, which facilitate the breakdown of the passive film [13]. On the other hand, corrosion mechanism of magnesium alloys in many other environmental conditions remains ill-defined. For instance, published investigations regarding corrosion of magnesium alloys in non-polluted atmospheres are rather scarce $[14,15]$.

Magnesium reveals a good resistance to oxidation at room temperature in dry environments [1618]. However, corrosion susceptibility increases with the relative humidity and the temperature. According to Splinter's theory the detrimental effect of relative humidity is associated with the dissociation of water vapour, which participates in the surface oxidation process, thus, the surface film thickens quicker at higher exposure to water vapour [19]. With regard to the influence of temperature, it has been suggested that, at low temperatures, the oxide film grows according to a Cabrera-Mott mechanism, where the thickness of the film is proportional to the temperature [20].

The presence of $\mathrm{NaCl}$ and/or $\mathrm{CO}_{2}$ in the atmosphere affects the mechanism of corrosion of magnesium alloys in humid environments. High corrosion susceptibility was found in the presence of $\mathrm{NaCl}$ and absence of $\mathrm{CO}_{2}$, with localized corrosion and formation of magnesium hydroxide as the main corrosion product [21]. On the other hand, in the presence of $350 \mathrm{ppm}$ of $\mathrm{CO}_{2}$ and $\mathrm{NaCl}$ concentrations in the range of $0-70 \mu \mathrm{g} / \mathrm{cm}_{2}$, several studies reported corrosion rates between 3 and 4 times lower compared with $\mathrm{CO}_{2}$-free atmospheres [22,23]. In the presence of $\mathrm{CO}_{2}$, corrosion mechanism appears in form of general corrosion with development of gray oxide film over the surface [24]. The increased corrosion resistance has been attributed to the formation of magnesium carbonates on the surface which may block the corrosion process [22]. 
Regarding the composition of the alloy, it is generally assumed that aluminium improves the corrosion resistance of magnesium alloys immersed in aqueous solutions containing chlorides. Alloys containing $8-10 \%$ aluminium are among the most corrosion resistant magnesium alloys [25]. However, apparently contradictory results are found in the literature, which could be due to different impurity levels or caused by differing microstructures as a result of the various processing methods [11]. In the case of atmospheric corrosion, Lindström [10] found corrosion rates increasing in the order $\mathrm{AZ91D}<\mathrm{AM} 60<\mathrm{AM} 20$ in $95 \%$ relative humidity at $22^{\circ} \mathrm{C}$, indicative of the positive effect of aluminium in the corrosion resistance of magnesium alloys exposed to humid air.

In most cases, the air-formed film on the surface of the magnesium alloy determines the atmospheric corrosion performance, however, little is known about its composition and correlation with the surface chemistry $[26,27]$. In the present study, XPS was used to investigate the surface of three commercial magnesium alloys, AZ31, AZ80 and AZ91D before exposition to constant humidity and temperature in a humidity chamber. For all the as-received materials, $\mathrm{MgO}, \mathrm{Mg}(\mathrm{OH})_{2}$ and magnesium carbonate were detected, with the latter being more evident on the magnesium alloys containing 8-9 wt.\% aluminium. The findings revealed that aluminium concentration in solid solution is a key factor for the amount of magnesium carbonate formed on the surface, and in the subsequent corrosion behaviour in the humid environment. The AZ80 alloy disclosed the highest amount of magnesium carbonate in the air-formed film and the lowest corrosion susceptibility in the humidity chamber.

\section{EXPERIMENTAL PROCEDURE}

\subsection{Test Materials}

Chemical compositions of the tested magnesium alloys, namely AZ31, AZ80 and AZ91D, are listed

in Table 1. Unalloyed commercially pure $\mathrm{Mg}$ was used as the reference material. Pure $\mathrm{Mg}$ and AZ31 alloy were fabricated in wrought condition, whereas AZ80 and AZ91D alloys were manufactured by casting process. All the materials were supplied by Magnesium Elektron Ltd. 


\subsection{Preparation and Surface Characterization}

For metallographic characterization, samples were wet ground through successive grades of silicon carbide abrasive papers from P120 to P2000 followed by diamond finishing to $0.1 \mu \mathrm{m}$. Two etching

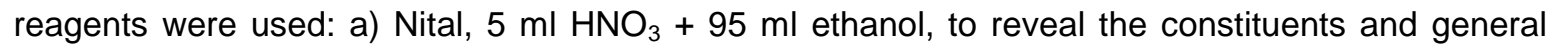
microstructure of $\mathrm{Mg}, \mathrm{AZ80}$ and AZ91D materials and b) Vilella reagent, $0.6 \mathrm{~g}$ picric acid $+10 \mathrm{ml}$ ethanol $+90 \mathrm{ml} \mathrm{H} \mathrm{H}_{2} \mathrm{O}$, to reveal grain boundaries of $\mathrm{AZ31}$ alloy. The constituents were examined by scanning electron microscopy (SEM) using a JEOL JSM-6400 microscope equipped with Oxford Link EDX microanalysis hardware.

\subsection{Gravimetric tests}

Specimens of working area $\sim 15 \mathrm{~cm}^{2}$ were used for the gravimetric measurements. Prior to the test, samples were wet ground through successive grades of silicon carbide abrasive papers to P1200, degreased in isopropyl alcohol in an ultrasonic bath, rinsed in deionized water, dried in warm air and weighed. The tests were carried out in a high relative humidity environment of $98 \%$ at $50^{\circ} \mathrm{C}$ during 28 days, simulated by a climatic cabinet CCK 300 (Dycometal). At the end of the tests, the specimens were rinsed with deionized water, dried in warm air and weighed again. Corrosion rate was calculated from the mass gain per unit of surface area, calculated from the expression $\left(M_{\mathrm{f}}-M_{\mathrm{i}}\right) / A$, where $M_{\mathrm{f}}$ is the final mass, $M_{\mathrm{i}}$ the initial mass and $A$ the exposed surface area. In all cases, the tests were performed twice to ensure the reproducibility of the results.

\subsection{Surface analysis}

Photoelectron spectra were acquired from the surface of mechanically polished magnesium alloys and stored during 7 days at room temperature and $50-60 \%$ relative humidity, using a Fisons MT500 spectrometer equipped with a hemispherical electron analyser (CLAM 2) and an Mg Ka X-ray source operated at $300 \mathrm{~W}$. The samples were mechanically fixed on small flat discs supported on an $\mathrm{XYZ}$ manipulator placed in the analysis chamber. The residual pressure in this ion-pumped analysis chamber was maintained below $10^{-8}$ Torr during data acquisition. The spectra were 
collected for 20-90 min, depending on the peak intensities at a pass energy of $20 \mathrm{eV}$, which is typical of high-resolution conditions. The intensities were estimated by calculating the area under each peak after smoothing and substraction of the S-shaped background and fitting the experimental curve to a mix of Lorentzian and Gaussian lines of variable proportion. Although sample charging was observed, accurate binding energies $(\mathrm{BE})$ could be determined by referencing to the adventitious $\mathrm{C} 1 \mathrm{~s}$ peak at $285.0 \mathrm{eV}$. Atomic ratios were computed from peak intensity ratios and reported atomic sensitivity factors [28].

For the acquisition of concentration profiles (distribution of elements as a function of specimen thickness) the surface was sputtered by argon ion bombardment (AIB). Bombardment was performed using an EXO5 ion gun incorporated into the equipment, provided with a scanning unit to track the beam, operating at a voltage of $5 \mathrm{kV}$, an intensity of $10 \mathrm{~mA}$ and a pressure of $1 \times 10^{-7}$ Torr. The sample current was $1 \mu \mathrm{A}$ during bombardment. According to information in the literature [29,30] this specimen current is equivalent to a sputtering rate of about $2 \AA / m i n$. Our results on interstitialfree (IF) steels, where we observed a sputtering rate of $1.5 \AA / \mathrm{min}$, leads us to believe that this is approximately the rate which has been obtained on specimens with the bombardment conditions and the spectrometer used in this study [31].

\section{RESULTS}

\subsection{Microstructure}

Microstructural observation of commercially pure $\mathrm{Mg}$ and AZ31 alloy revealed equiaxial grains and some $\mathrm{Mn}-\mathrm{Al}$ inclusions for the latter (Figures 1a-1b). For the AZ80 and AZ91D alloys, although aluminium concentration is below the maximum solid solubility in magnesium, a two-phase microstructure was observed due to nonequilibrium conditions during the solidification process. AZ80 alloy disclosed $\alpha-M g$ grains and a discontinuous precipitation of $\beta$-phase $\left(\mathrm{Mg}_{17} \mathrm{Al}_{12}\right)$ in lamellar form (Figure 1C). AZ91D alloy revealed $\alpha-M g$ primary dendrites and eutectic $\alpha-M g / M g{ }_{17} A I_{12}$ in the interdendritic region, which appears in partially divorced form with respect to solid solution (Figure $1 d)$. 


\subsection{XPS analysis of the air-formed films}

Figure 2 shows a comparison of the high-resolution C1s XPS spectra of (a) AZ91D, (b) AZ80, (c) AZ31 and (d) Mg materials. The spectra can be fitted using two components at different binding energies: at $285.0 \mathrm{eV}$, which may be associated with the presence of $\mathrm{C}-\mathrm{C} / \mathrm{C}-\mathrm{H}$ groups; and a less intense component at $289.2 \mathrm{eV}$ associated with the presence of magnesium carbonate [30]. The first component, $\mathrm{C}-\mathrm{C} / \mathrm{C}-\mathrm{H}$ groups, appears on the surface (<3nm in thickness) of almost any metal in contact with the atmosphere at room temperature, irrespective of its composition. Magnesium carbonate formation can be explained by diffusion of $\mathrm{CO}_{2}$ from the environment and reaction with the air-formed film [12].

After 10 min of AIB the intensity of the component associated with the $\mathrm{C}-\mathrm{C} / \mathrm{C}-\mathrm{H}$ groups significantly decreased. On the other hand, no important variations were observed for the component associated with the presence of magnesium carbonate (Figs 2e-2h). Table 2 shows the atomic percentages of magnesium carbonate calculated from the C1s spectra (Fig. 2). It is important to mention that, the magnesium carbonate percentage increased with the aluminium concentration in the composition of the alloy. This is more evident after $10 \mathrm{~min}$ of AIB, when the contaminated external film was partially removed.

The high-resolution O1s XPS spectra (Figure 3) of the orginal surface of (a) AZ91D, (b) AZ80, (c) AZ31 and (d) Mg materials revealed one component at a binding energy of $532.0 \mathrm{eV}$ associated with the presence of oxygen in the form of magnesium carbonate and $\mathrm{Mg}(\mathrm{OH})_{2}$, and another two binding energies, less intense, at 530.5 and $533.5 \mathrm{eV}$, which can be interpreted as oxygen in the form of $\mathrm{MgO}$ and $\mathrm{H}_{2} \mathrm{O}$, respectively. After $10 \mathrm{~min}$ of $\mathrm{AIB}$, the intensity of the component associated

with $\mathrm{MgO}$ increased and the component at $532.0 \mathrm{eV}$, related to $\mathrm{CO}_{3}{ }^{2-} / \mathrm{Mg}(\mathrm{OH})_{2}$, decreased. The $\mathrm{H}_{2} \mathrm{O}$ component dissappeared after 10 min of argon sputtering (Figs 3e-3g). 
The high-resolution Mg2p XPS spectra disclosed a single component at a binding energy of 50.5 $\mathrm{eV}$. This binding energy is typical of magnesium in its oxidised form $\mathrm{Mg}^{2+}$. This component remained stable after 10 min of AIB (approximately 20 Á of eliminated thickness) (Figure 4).

\subsection{Gravimetric tests}

Mass gain variation versus time of magnesium-aluminium alloys exposed to $98 \%$ relative humidity at $50^{\circ} \mathrm{C}$ in the humidity cabinet revealed two stages (Figure 5). i) 0-5 days; unlike the commercially pure $\mathrm{Mg}$, mass loss predominated for the magnesium-aluminium alloys. The AZ80 and AZ91D alloys revealed the highest mass loss after 2 days of exposition in the humid environment with values in the range of $-0.050-0.075 \mathrm{mg} / \mathrm{cm}^{2}$. ii) 5-30 days; mass gain following approximately linear kinetics was found for all tested materials. Pure Mg presented the highest mass gain, namely $0.019 \mathrm{mg} \mathrm{cm}^{-2} \mathrm{~d}^{-1}$. The addition of aluminium increased the corrosion resistance. Thus, $3 \mathrm{wt} \%$ aluminium in AZ31 alloy reduced the mass gain to $0.017 \mathrm{mg} \mathrm{cm}^{-2} \mathrm{~d}^{-1}$, and $8-9 \mathrm{wt} . \%$ aluminium in the AZ80 and AZ91D alloys diminished the mass gain to $0.012 \mathrm{mg} \mathrm{cm}^{-2} \mathrm{~d}^{-1}$ and $0.013 \mathrm{mg} \mathrm{cm}^{-2} \mathrm{~d}^{-1}$, respectively. In the last days of exposition, the mass gain average rate diminished for all tested materials indicating formation of a slightly protective film on the surface. This in accordance with other atmospheric corrosion tests on magnesium alloys [32].

\section{DISCUSSION}

It is known that when magnesium is exposed to humid air, its surface is getting covered with a magnesium oxide/hydroxide film of few nanometers [23,33,34]. According to Nordlien [31] the film formed on magnesium-aluminium alloys exposed to $65 \%$ relative humidity reveals a two-layered structure with a cellular, inner layer covered by a thin dense layer. The $\mathrm{CO}_{2}$ present in the air readily diffuses into this layer, reacting and forming magnesium carbonate [12,34], which has been reported to reduce the susceptibility to localized corrosion of magnesium exposed to humid air [23].

In general, aluminium improves the corrosion resistance of magnesium alloys exposed to aqueous solutions containing chlorides. The reason for this is still not clear, though the general accepted 
idea is the $\beta$-phase network acting as a barrier for corrosion progress. Other explanation is the accumulation of aluminium oxide species at the metal/oxide interface; Hehmann [2] suggested the presence of a protective film enriched with aluminium. According to Nordlien et al. [31], this film becomes more compact and protective as aluminium content in the bulk alloy increases. And, from their experiments, Song et al. [4] deduced that alloy surface film is made up of three layers, a middle layer consisting mainly of $\mathrm{MgO}$, an outer layer of $\mathrm{Mg}(\mathrm{OH})_{2}$, and an inner $\mathrm{Al}_{2} \mathrm{O}_{3}$ rich layer. This last one, formed as a result of the stronger affinity of aluminium for oxygen compared with magnesium if $\mathrm{pH}$ is close to neutral, as may be the case at the alloy/film interface. However, to the best of the authors' knowledge the influence of aluminium concentration in the bulk alloy on the amount of carbonate formed on the metal surface and the subsequent atmospheric corrosion resistance has not been previously reported in the literature.

XPS results revealed that the naturally formed film on studied magnesium alloys stored at room temperature consisted of $\mathrm{MgO}, \mathrm{Mg}(\mathrm{OH})_{2}$ and magnesium carbonate, the latter being more evident as the aluminium concentration in the bulk alloy increased (Figure 6). The increase of carbonate amount was accompanied by a reduction of $\mathrm{MgO}$ and $\mathrm{Mg}(\mathrm{OH})_{2}$; i.e. for the $\mathrm{AZ80}$ and AZ91D alloys, carbonate to oxide/hydroxide ratio was close to 1 (Figure 6). It is important to mention an inverse trend for the $\operatorname{AZ80}(8.2 \% \mathrm{Al})$ and $\mathrm{AZ91D}(8.8 \% \mathrm{Al})$ alloys, since the carbonate proportion is lower for the latter. This deviation is larger than the scatter in carbonate measurements (accuracy within \pm $2 \%)$ and is indicative that, apart from aluminium concentration in the bulk composition, the alloy microstructure also influences the amount of magnesium carbonate formed on the surface.

Gravimetric measurements of specimens exposed to $98 \%$ and $50^{\circ} \mathrm{C}$ during 28 days disclosed initial mass loss only for the magnesium-aluminium alloys. It is known that, in humid environments the surface is covered with a thin electrolyte film, which due to lack of convection facilitates concentration gradients as well as potential gradients, hence, the cathodic areas will experience high $\mathrm{pH}$ values whereas the electrolyte at the anodic sites will tend to exhibit low $\mathrm{pH}[10]$. It is suggested here that, the high $\mathrm{pH}$ in the cathodic areas increases the solubility of aluminium, 
therefore the higher mass losses for the AZ80 and AZ91D alloys compared with the $\mathrm{Mg}$ and $\mathrm{AZ31}$ materials could be related to preferential dissolution of aluminium under these conditions. For increased exposure times, all tested materials followed mass gain with approximately linear kinetics, commonly associated with the absortion of $\mathrm{H}_{2} \mathrm{O}$ and $\mathrm{CO}_{2}$ and formation of a non-protective corrosion products layer on the surface. At the end of the experiment, the corrosion layer exhibited some protection since the average corrosion rate diminished. The AZ80 revealed the lowest mass gain at the end of the experiment. Similar results were found by Pardo et al. [25] comparing the same alloys after immersion in $3.5 \mathrm{wt} . \% \mathrm{NaCl}$ at room temperature.

It is suggested here that it is the amount of aluminium in solid solution which determines corrosion susceptibility in humid air rather than the $\beta$-phase distribution. According to this, the AZ80 alloy reveals a biphasic microstructure with $\alpha-\mathrm{Mg}$ solid solution and discontinuous precipitation in lamellar form of $\beta$-phase $\left(\mathrm{Mg}_{17} \mathrm{Al}_{12}\right)$ (Figure 1c). The $\alpha-\mathrm{Mg}$ dendrites presenting 13.3 at.\% aluminium [25]. On the other hand, the AZ91D alloy, due to a higher solidification rate, reveals lower amount of aluminium in the $\alpha$-phase, namely 8.4 at\%, and greater aluminium segregation in the interdendritic spaces (Figure 1d) [25]. Hence, it is likely that the AZ80 alloy revealed higher corrosion resistance compared with the AZ91D alloy due to a higher amount of aluminium in solid solution.

Plotting mass gain variation during the humidity test against amount of magnesium carbonate formed in the original air-formed film revealed a linear relationship (Figure 7), indicating that there is a direct influence between these two parameters. The beneficial effect of magnesium carbonates on atmospheric corrosion resistance of magnesium alloys is already known. The dissolution of $\mathrm{CO}_{2}$ in the surface electrolyte will tend to neutralize the alkali formed in the cathodic reaction [35]:

$$
\begin{gathered}
\mathrm{CO}_{2}(\mathrm{aq})+\mathrm{H}_{2} \mathrm{O} \leftrightarrow \mathrm{HCO}_{3}^{-}+\mathrm{H}^{+} \mathrm{pKa}=6.65 \\
\mathrm{HCO}_{3}{ }^{-} \leftrightarrow \mathrm{CO}_{3}{ }^{2-}+\mathrm{H}^{+} \mathrm{pKa}=10.33
\end{gathered}
$$


Initially, the reduced $\mathrm{pH}$ in the surface electrolyte increases the rate of dissolution of the air-formed film. Then the hydroxide ions generated in the cathodic reaction or dissolved from the film react with carbonic acid forming magnesium carbonate, which enhance the corrosion performance of magnesium alloys in humid air. In case of aluminium alloys, aluminium carbonate does not form, because, unlike magnesium carbonate, it is not stable in humid air [36]. However as a consequence of the lower $\mathrm{pH}$ caused by the protolysis of carbonic acid $(1,2)$ solubility of alumina decreases and the stability of the passive film increases.

The findings of the present work suggest that the higher the amount of aluminium in solid solution the higher is the amount of magnesium carbonate formed on the surface and subsequently the better is corrosion resistance in humid air. The explanation for this is still not clear and need further research. It may be related to higher porosity of the oxide/hydroxide film formed on the surface of magnesium-aluminium alloys, facilitating higher diffusion of $\mathrm{CO}_{2}$, or may be due to the presence of $\mathrm{Al}^{3+}$ in the surface electrolyte.

Future work is planned in order to investigate the influence of the alloy composition/microstructure on the morphology of the corrosion attack and on the amount of magnesium carbonate formed during exposition to humid air.

\section{CONCLUSIONS}

1. The air-formed film on commercially pure magnesium consisted of $\mathrm{MgO}, \mathrm{Mg}(\mathrm{OH})_{2}$ and a slight quantity of magnesium carbonate. Increasing aluminium concentration in $\mathrm{Mg}-\mathrm{Al}$ alloys resulted in greater magnesium carbonate formation and lower amounts of $\mathrm{MgO}$ and $\mathrm{Mg}(\mathrm{OH})_{2}$. For the $\mathrm{AZ80}$ and AZ91D alloys with 8-9 wt\% aluminium content near $50 \%$ of $\mathrm{Mg}$ atoms in the surface film are combined in the form of magnesium carbonate. 
2. An inverse correlation is obtained when the amount of carbonate in the original air-formed film is plotted against mass gain variation during the subsequent humidity test. The results suggest an important role of the alloying aluminium in the mechanisms that determine both magnitudes.

3. The detailed examination of the results for the AZ80 and AZ91D alloys (with a similar composition but different microstructure), suggests the involvment of some other effect, besides the simple aluminium content, on the commented general results. It seems probable that this effect is related with aluminium distribution in the alloy microstructure, particularly with the amount of aluminium in solid solution.

\section{REFERENCES}

1. 1. O.Lunder, J.E. Lein, T. Kr. Aune, K. Nisancioglu, Corrosion, 45 (1989), 741.

2. F. Hehmann, F. Sommer, H. Jones, R.G.J. Edyvean, J.Mat. Sci., 24 (1989) 2369.

3. G. L. Makar, J. Kruger, J. Electrochem. Soc., 137 (1990) 414.

4. G. Song, A. Atrens, X. Wu, B. Zhang, Corros. Sci., 40 (1998) 1769.

5. G. Song, A. Atrens, M. Dargush, Corros. Sci., 41 (1999), 249.

6. C.B. Baliga, P. Tsakiropolous, Mat. Sci. Tech., 9 (1993) 513.

7. J.K. Lin, C. L. Hsia, J.Y. Uan, Scripta Materalia, 56 (2007) 927.

8. O. Lunder, J.E. Lein, T.K. Aune, K. Nisancioglu, J. Electrochem. Soc., 134 (1987) C109.

9. R. Lindström, J.E. Svensson, A.G. Johsnsson, J. Electrochem. Soc., 147 (2000), 1751.

10. R. Lindström, J.E. Svensson, A.G. Johsnsson, J. Electrochem. Soc., 149 (2002), B103.

11. G. Ballerini, U. Bardi, R. Bignucolo, G. Ceraolo, Corros. Sci., 47 (2005), 2173.

12. M. Jönson, D. Persson, D.Thierry, Corros. Sci., 49 (2007) 1540.

13. G. Song, A. Atrens, Adv. Eng. Mater. 9 (2007) 177.

14. H.P. Godard, W.B. Jepson, M.R. Bothwell, R.L. Kane (Eds.) The corrosion of Light Metals, John Wiley and Sons, New York, 1967.

15. L. Whitby, Trans. Faraday Soc 29 (1933) 844. 
16. G. Song, A. Atrens, Adv. Eng. Mater. 5 (2003) 837.

17. G. Song, A. Atrens, Adv. Eng. Mater. 1 (1999) 11.

18. H. Alves, U. Koster, E. Aghion, D. Eliezer, Matrice Technology Limited, Materials Technology $16(2001) 110$.

19. S.J. Splinter, N.S. Mclntyre, W.N. Lennard, K. Griffiths, G. Palumbo, Surf. Sci. 292 (1993) 130.

20. N. Cabrera, N.F. Mott, Reports on Progress in Physics 12 (1948) 163.

21. R. Lindström, Ph. D. thesis, Göteborg University, Göteborg, 2003.

22. R. Lindström, L.G. Johansson, J.E. Svensson, Materials and Corrosion 54 (2003) 587.

23. R. Lindström, L.G. Johansson, G.E. Thompson, P. Skeldon, J.E. Svensson. Corrosion Science 46 (2004) 1141.

24. H.D. Hui, A.A. Mikhajlov, Y.N. Mikhajlovskij, P.V. Strekalov, D. T. Bin, Protection of Metals 30 (1994) 506.

25. A. Pardo, M.C. Merino, A.E. Coy, R. Arrabal, F. Viejo, E. Matykina, Corrosion Science (2008) In press.

26. V. Fournier, P. Marcus, I. Olejford, Surf. Interf. Anal. 34 (2002) 494.

27. J.H. Nordlien, K. Nisancioglu, S. Ono, N. Masuko, J. Electrochem. Soc. 144 (1997) 461.

28. C.D. Wagner, L.E. Davis, M.V. Zeller, J.A. Taylor, R.H. Raymond and L. Gale. Surf. Interface. Anal. 3 (1981), pp. 211.

29. E. McCafferty, M.K. Bernett and J.S. Murday, Corros. Sci., 28 (1982) 559.

30. P.T. Moseley, G. Tappin and J.C. Riviere, Corros. Sci., 22 (1982) 69.

31. S. Feliu (Jr), M.L. Perez-Revenga, Metall. Mater. Trans. A 35A (2004) 2039.

32. D.V. Vy, A.A. Mikhajlov, Y.N. Mikhajlovskij, P.V. Strekalov, T.B. Do, Zaschita Metallov 30 (1994) 578.

33. J.H. McIntyre, C. Chen, Corros. Sci., 40 (1998) 1967.

34. C. Fotea, J. Callaway, M.R. Alexander, Surf. Interface. Anal. 38 (2006), 1363.

35. R.M. Smith, A.E. Martell, in: Critical Stability Constants, Vol. 4, Plenum Press, New York, 1973.

36. P. Pascal, Nuveau Traité de Chimie Mineral, Masson et Cie, eds., Paris (1968), Vol 8, pp. 746, 749. 
Acknowledgements. The authors wish to thank the MCYT for the financial support given to this work (Project MAT2006-13179-C02-01-02). 


\section{FIGURE CAPTIONS}

Table 1. Chemical composition of tested materials (wt.\%).

Tabla 2. Atomic percentage observed by XPS in the external surface of AZ91D, AZ80, AZ31 and Mg materials.

Figure 1. Microstructures of the tested magnesium materials: (a) Commercialy pure Mg; (b) AZ31 alloy; (c) AZ80 alloy; (d) AZ91D alloy.

Figure 2. High resolution $\mathrm{C} 1 \mathrm{~s}$ spectra obtained before and after $10 \mathrm{~min}$ of argon sputtering of the air-formed film on (a,e) AZ91D, (b,f) AZ80, (c,g) AZ31 and (d,h) Mg materials.

Figure 3. High resolution O1s spectra obtained before and after $10 \mathrm{~min}$ of argon sputtering of the air-formed film on (a,e) AZ91D, (b,f) AZ80, (c,g) AZ31 and (d,h) Mg materials.

Figure 4. High resolution Mg2p spectra obtained before and after 10 min of argon sputtering of the air-formed film on (a,e) AZ91D, (b,f) AZ80, (c,g) AZ31 and (d,h) Mg materials.

Figure 5. Mass gain variation of studied magnesium alloys exposed to $98 \%$ relative humidity and $50^{\circ} \mathrm{C}$.

Figure 6. Correlation between aluminium concentration and magnesium oxide/hydroxide to magnesium carbonate ratio, after removal of the thin organic layer due to carbonaceous contamination.

Figure 7. Mass gain versus percentage of magnesium carbonate in the air-formed film before the humidity test. 
Table 1

\begin{tabular}{|c|c|c|c|c|c|c|c|c|c|c|}
\hline \multirow{2}{*}{ Material } & \multicolumn{10}{|c|}{ Elements (wt.\%) } \\
\hline & $\mathrm{Al}$ & $\mathrm{Zn}$ & $\mathrm{Mn}$ & $\mathrm{Si}$ & $\mathrm{Cu}$ & $\mathrm{Fe}$ & $\mathrm{Ni}$ & $\mathrm{Ca}$ & $\mathrm{Zr}$ & Others \\
\hline $\mathrm{Mg}$ & 0.006 & 0.014 & 0.03 & 0.019 & 0.001 & 0.004 & $<0.001$ & & & \\
\hline AZ31 & 3.1 & 0.73 & 0.25 & 0.02 & $<0.001$ & 0.005 & $<0.001$ & $<0.01$ & $<0.001$ & $<0.30$ \\
\hline AZ80 & 8.2 & 0.46 & 0.13 & 0.01 & $<0.001$ & 0.004 & & & & $<0.30$ \\
\hline AZ91D & 8.8 & 0.68 & 0.30 & 0.01 & $<0.001$ & 0.004 & $<0.008$ & & & $<0.30$ \\
\hline
\end{tabular}


Table 2

\begin{tabular}{|c|c|c|c|c|c|}
\hline \multirow[b]{2}{*}{ Material } & \multicolumn{5}{|c|}{ Elements (at.\%) } \\
\hline & C & $\mathrm{O}$ & $\mathrm{Mg}$ & $\mathrm{Al}$ & $\begin{array}{l}\mathrm{CO}_{3}{ }^{2-} \\
\text { (obtained from the fiting } \\
\text { of the } \mathrm{C} 1 \mathrm{~s} \text { peak and the } \\
\mathrm{C} \text { atomic percentage) }\end{array}$ \\
\hline & \multicolumn{5}{|c|}{ Original surface (without AIB) } \\
\hline AZ91D & 45 & 37 & 16 & 2 & 8 \\
\hline AZ80 & 46 & 41 & 11 & 2 & 8 \\
\hline$A Z 31$ & 50 & 36 & 14 & 0 & 6 \\
\hline \multirow[t]{2}{*}{$\mathrm{Mg}$} & 56 & 32 & 12 & 0 & 6 \\
\hline & \multicolumn{5}{|c|}{ After 10 min of AIB } \\
\hline AZ91D & 13 & 59 & 25 & 3 & 8 \\
\hline AZ80 & 12 & 60 & 25 & 3 & 9 \\
\hline AZ31 & 13 & 60 & 27 & 0 & 6 \\
\hline $\mathrm{Mg}$ & 18 & 55 & 27 & 0 & 3 \\
\hline
\end{tabular}




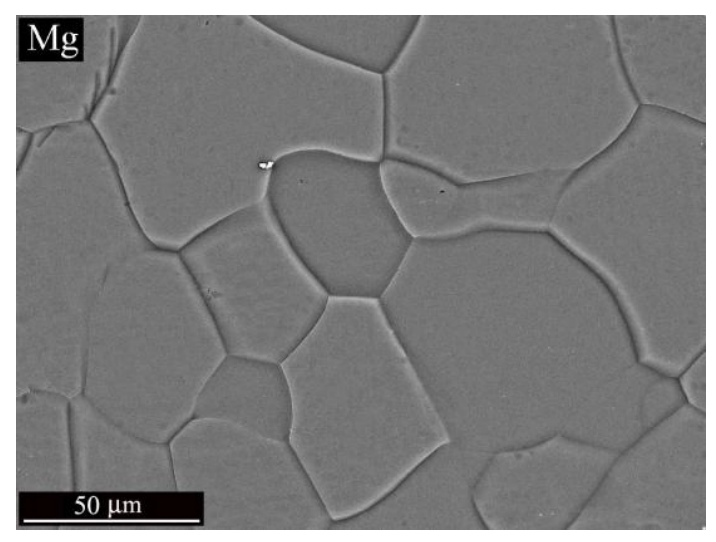

(a)

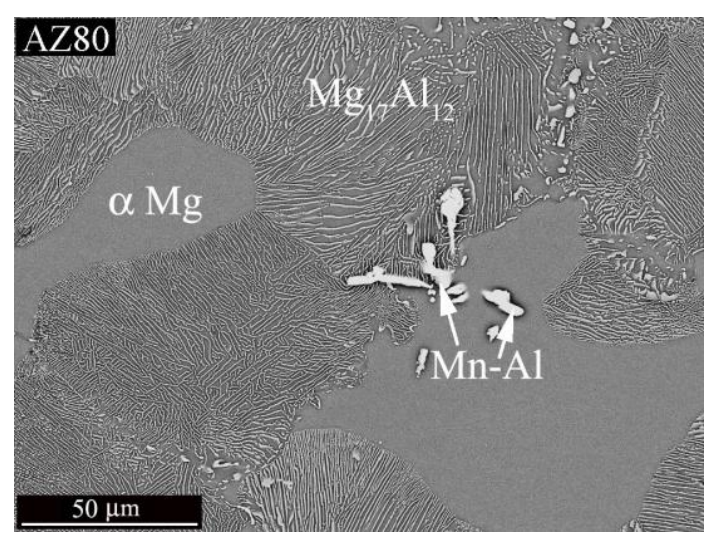

(c)

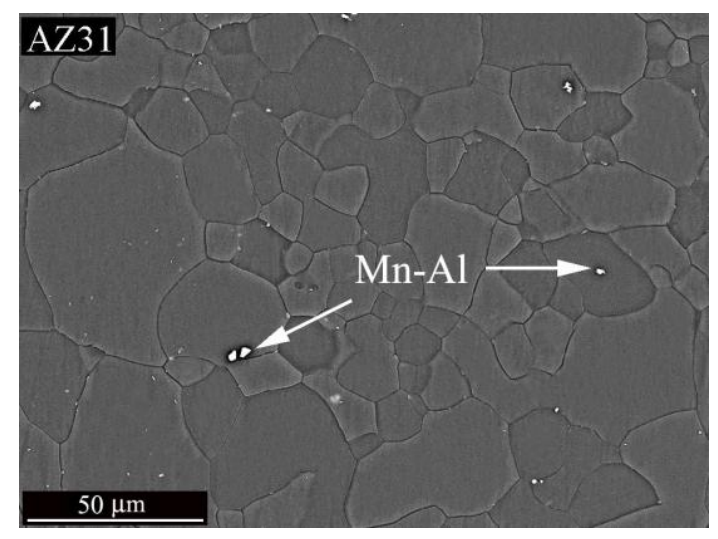

(b)

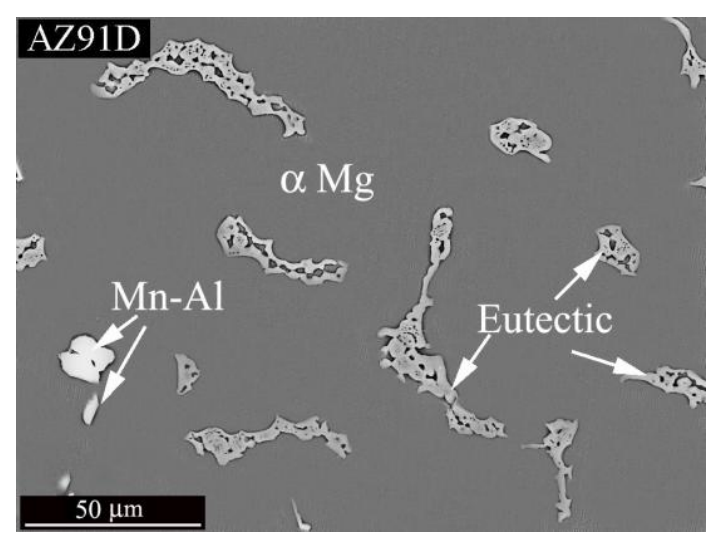

(d)

Figure 1 


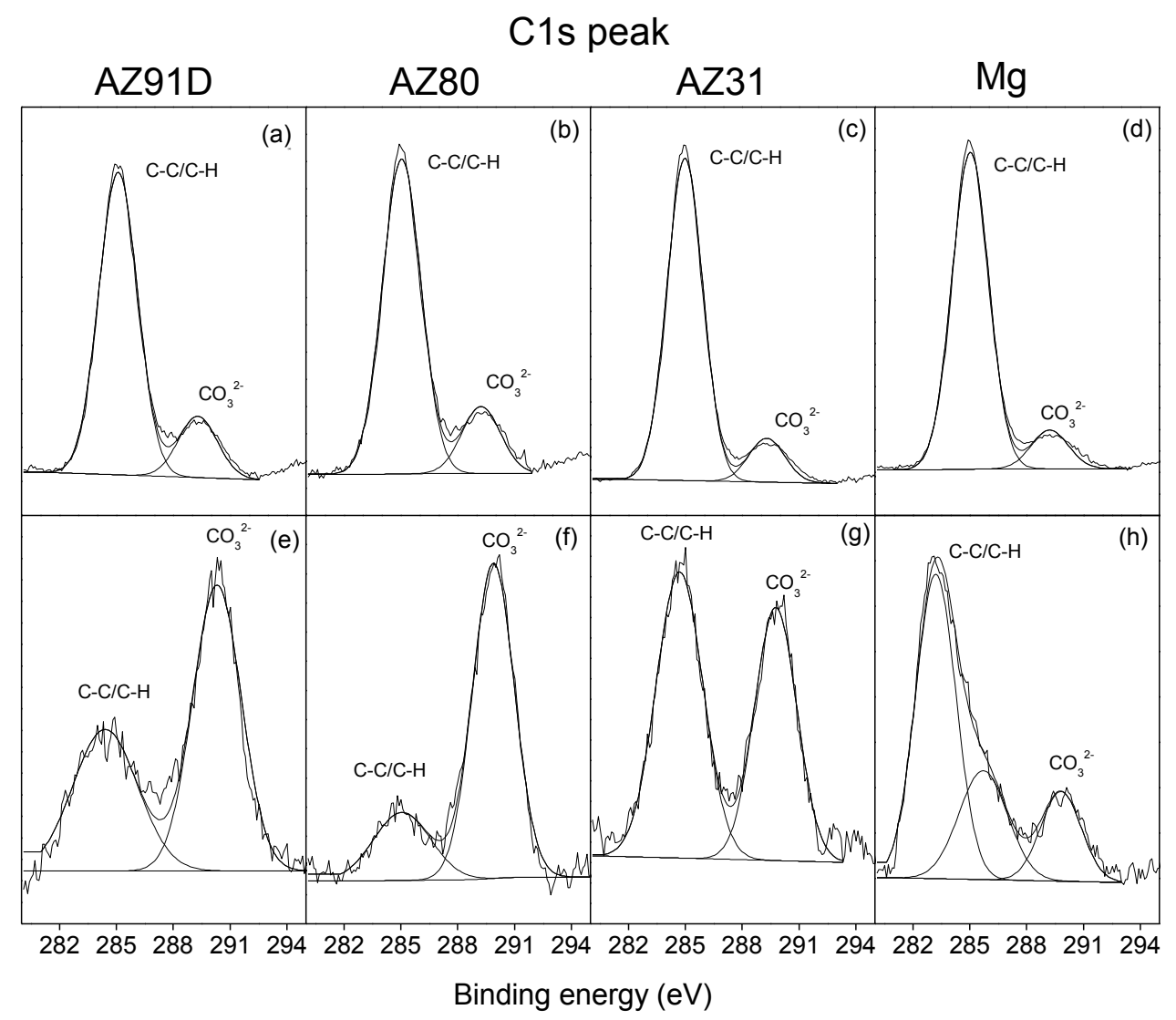

Figure 2

Figure 3 


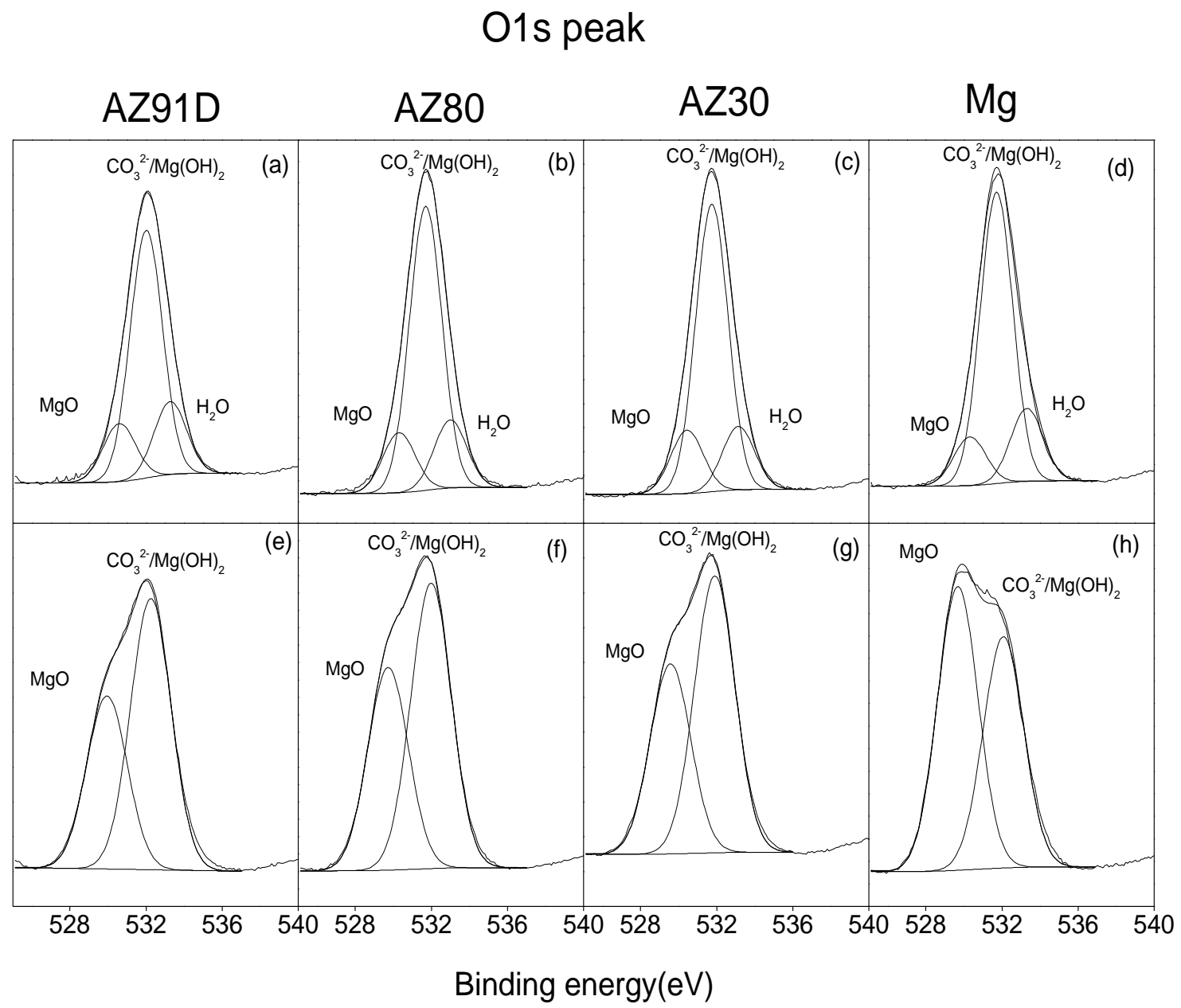

Figure 3 


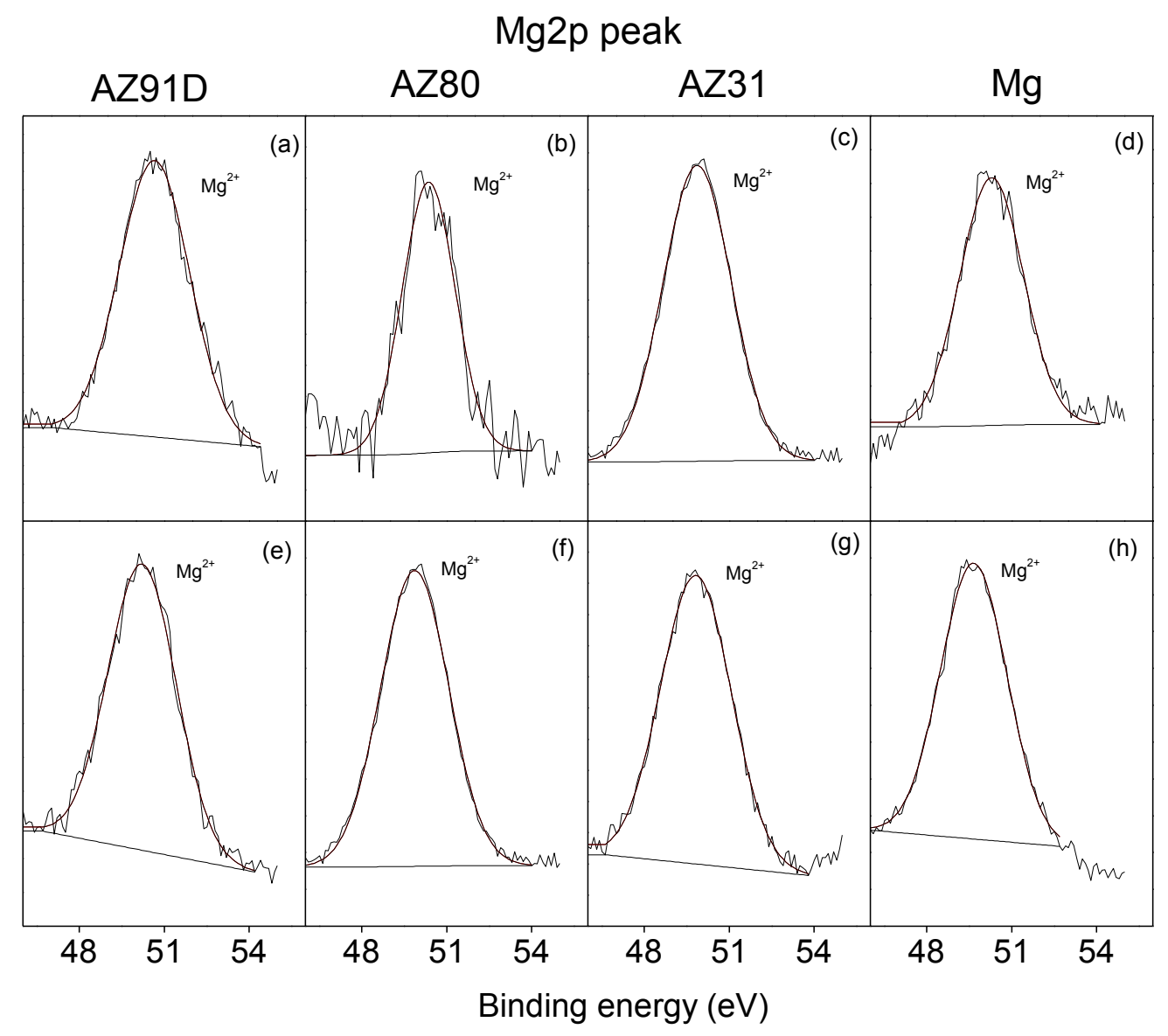

Figure 4 


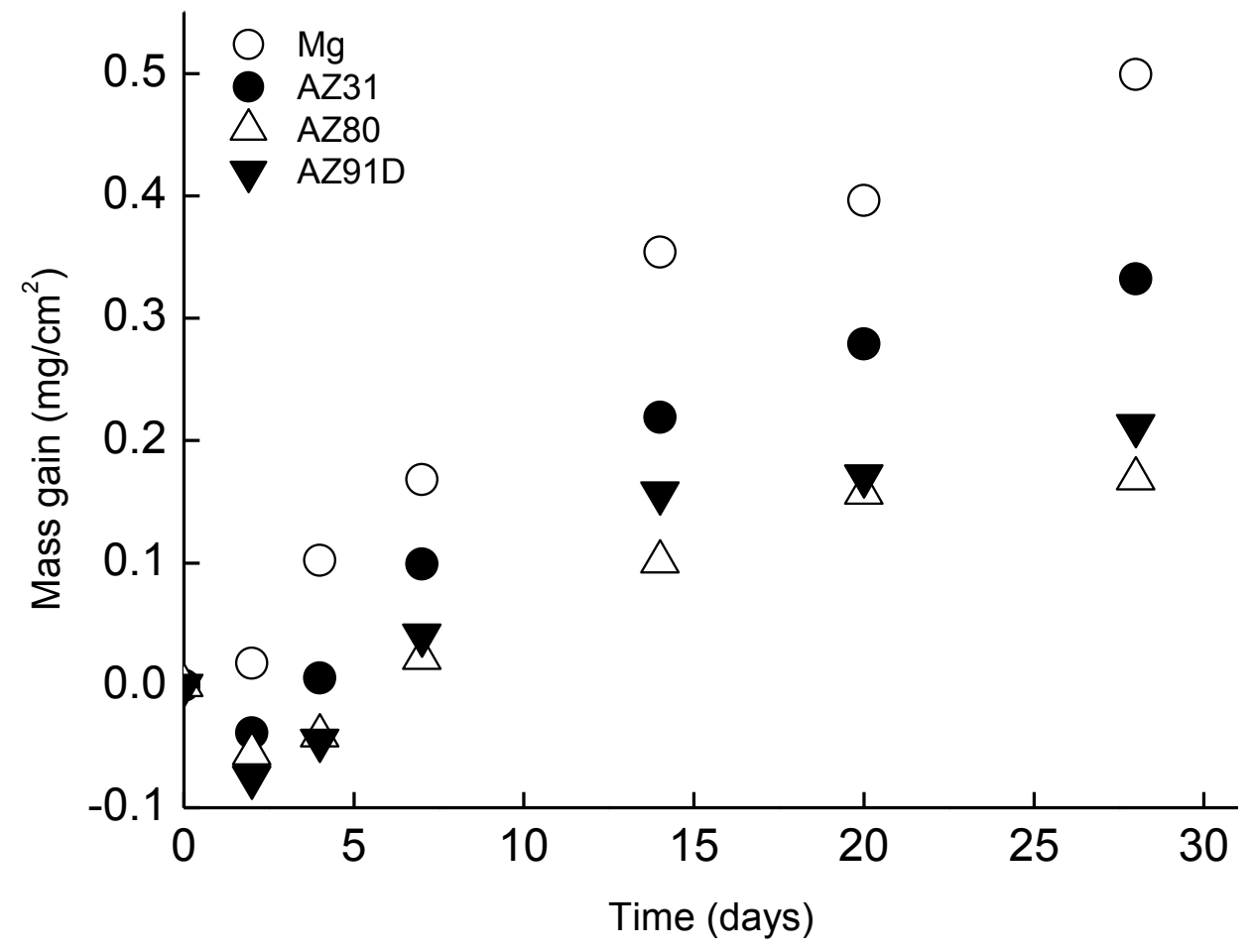

Figure 5 


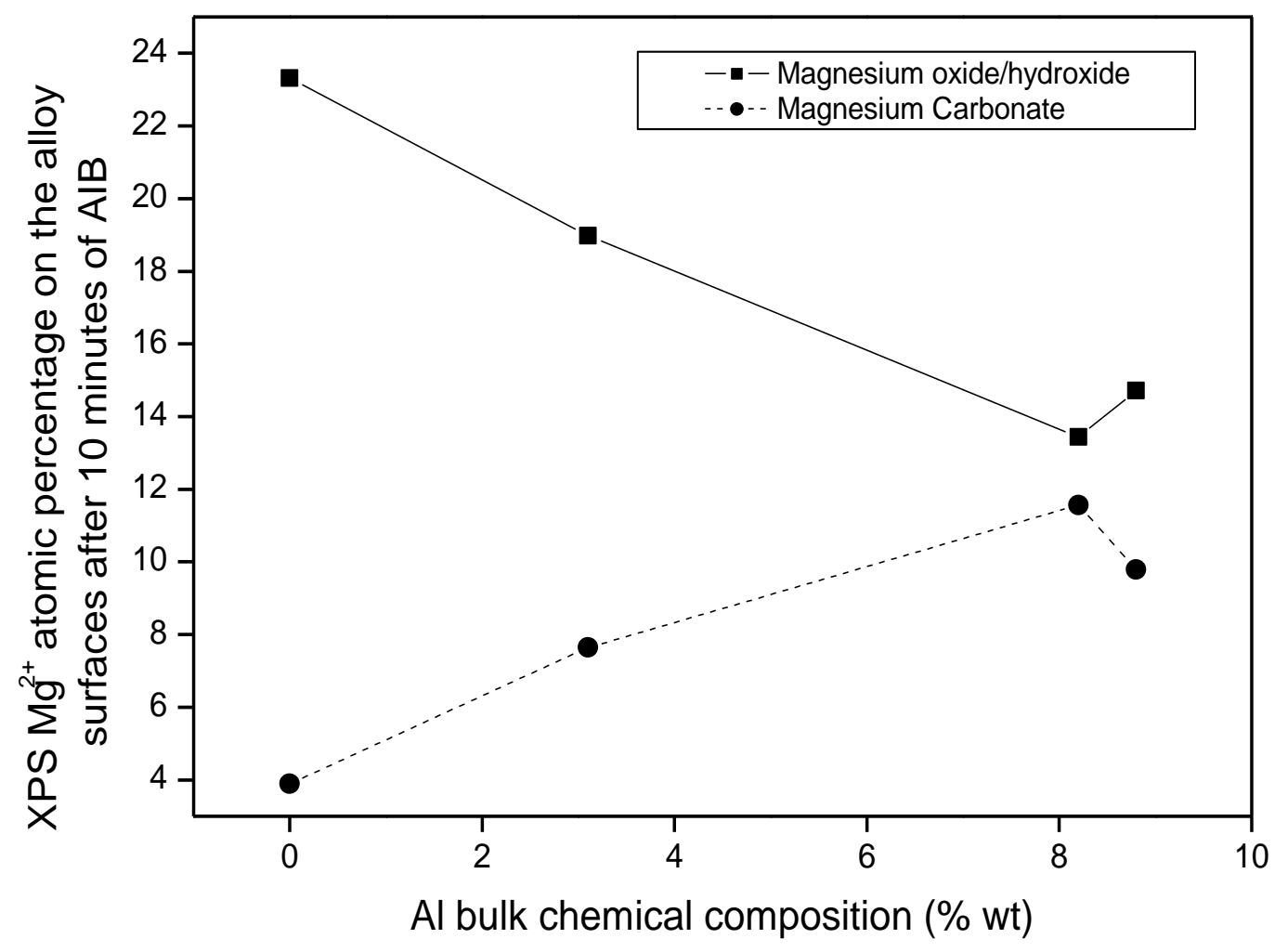

Figure 6 


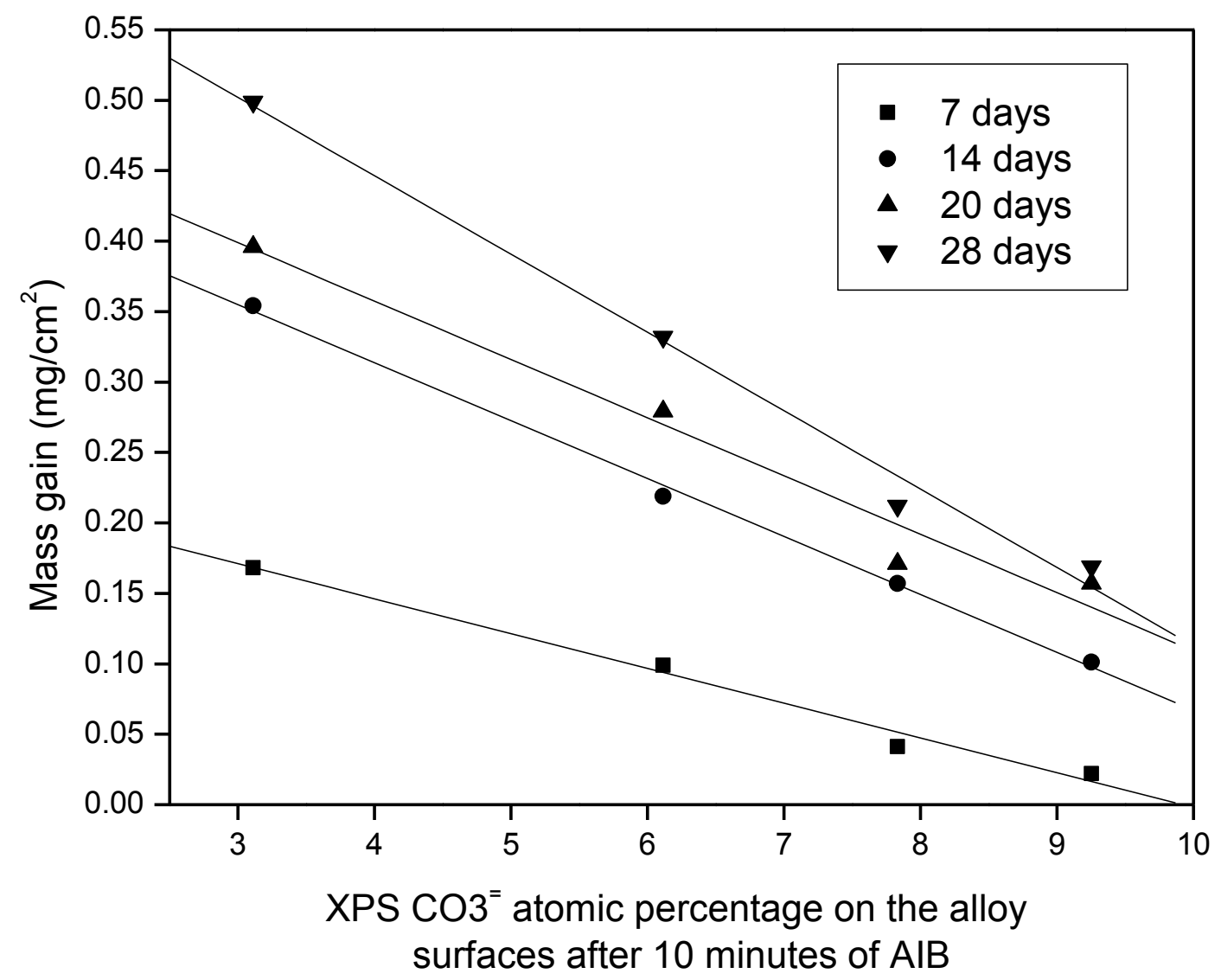

Figure 7 